\title{
KIT, NRAS and BRAF mutations in sinonasal mucosal melanoma: a study of 56 cases
}

\author{
A Zebary ${ }^{*}, 1,3$, M Jangard ${ }^{2,3}, \mathrm{~K}$ Omholt ${ }^{1}$, B Ragnarsson-Olding ${ }^{1}$ and J Hansson ${ }^{1}$ \\ ${ }^{1}$ Department of Oncology-Pathology, Cancer Center Karolinska, Karolinska Institutet, Stockholm, Sweden and ${ }^{2}$ Department of \\ Oto-Rhino-Laryngology, Head and Neck Surgery, Karolinska Institutet, Karolinska University Hospital, Stockholm, Sweden
}

Background: Mucosal melanomas in the head and neck region are most frequently located in the nasal cavity and paranasal sinuses. Sinonasal mucosal melanoma (SNMM) comprises $<1 \%$ of all melanomas. The aim was to determine the KIT, NRAS and $B R A F$ mutation frequencies in a large series of primary SNMMs.

Methods: Laser capture microdissection was used to isolate tumour cells from 56 formalin-fixed paraffin-embedded tumours. The tumour cells were screened for KIT, NRAS and BRAF mutations by direct sequencing.

Results: Overall, 21\% (12 out of 56) of SNMMs harboured KIT, NRAS or BRAF mutations. Mutations in these oncogenes occurred in a mutually exclusive manner. Both KIT and BRAF mutations were identified at a similar frequency of $4 \%$ each (2 out of 56$)$, whereas NRAS mutations were detected in 14\% (8 out of 56) of the SNMMs. Four of the NRAS mutations were located in exon 1. Mutations in these oncogenes were significantly more common in melanomas located in the paranasal sinuses than in nasal cavity $(P=0.045)$. In a multivariate analysis, patients with melanomas in the nasal cavity had a significantly better overall survival than those with tumours in the paranasal sinuses $(P=0.027)$.

Conclusion: Our findings show that KIT and BRAF mutations, which are accessible for present targeted therapies, are only rarely present in SNMMs, whereas NRAS mutations seem to be relatively more frequent. The data show that majority of SNMMs harbour alterations in genes other than KIT, NRAS and BRAF.

Approximately 1-2\% of all melanomas originate from the mucosal membranes in the digestive, respiratory and genitourinary tracts (Clifton et al, 2011; The National Board of Health and Welfare (1960-2009)). Mucosal melanomas in the head and neck region are most frequently located in the nasal cavity, followed by paranasal sinuses and oral cavity (Jethanamest et al, 2011). Primary sinonasal mucosal melanoma (SNMM), however, comprises $<1 \%$ of all melanomas (Clifton et al, 2011), and conversely, SNMMs amount to only $1-9 \%$ of all malignant lesion of the nasal tract (Harbo et al, 1997; Norlander et al, 2003).

The incidence of SNMM in Sweden has increased significantly from 1960 through 2000, although not at the same pace as that of cutaneous melanoma (Jangard et al, 2013). For women, the incidence has doubled and for men it almost tripled comparing 1960-1964 vs 1995-2000. Patients with SNMM have a poor prognosis with 5-year survival rates of 20-28\% (Lund et al, 2012; Jangard et al, 2013).

The mitogen-activated protein kinase and phosphatidylinositol3 kinase-Akt pathways have critical roles in the pathogenesis of melanoma. Activation of these pathways in cutaneous and mucosal melanomas commonly occur through activating mutations in the $B R A F, N R A S$ and KIT genes (Jovanovic et al, 2008; Omholt et al, 2011). However, mucosal melanomas have a distinct genetic background compared with cutaneous melanomas. For example, the frequency of BRAF mutation is significantly higher in melanoma arising in the trunk and skin without chronic sun damage than in mucosal melanomas (Curtin et al, 2005; Ellerhorst et al, 2011; Lee et al, 2011). On the other hand, NRAS mutations are frequently detected in melanomas located in extremities and skin with chronic sun damage (Ellerhorst et al, 2011; Lee et al,

\footnotetext{
*Correspondence: Dr A Zebary; E-mail: sattar.zebary@ki.se
}

${ }^{3}$ These authors contributed equally to this work.

Received 4 April 2013; revised 13 June 2013; accepted 22 June 2013; published online 16 July 2013

(c) 2013 Cancer Research UK. All rights reserved 0007-0920/13 
2011). Mucosal melanomas frequently harbour mutations and/or amplifications of the KIT gene, but very rarely contain BRAF mutations (Curtin et al, 2006; Beadling et al, 2008). Approximately 50 and $20 \%$ of cutaneous melanomas harbour BRAF and NRAS mutations, respectively (Davies et al, 2002; Omholt et al, 2003; Edlundh-Rose et al, 2006; Lee et al, 2011), whereas KIT mutations are detected in about $<2 \%$ of melanomas in skin without chronic sun damage (Curtin et al, 2006; Handolias et al, 2010).

Interestingly, in a recent study of mucosal melanomas from several different sites, we found a significantly higher frequency of KIT mutations in vulvar melanomas compared with tumours of other sites (35\% vs 10\%), suggesting that the KIT mutation rate in mucosal melanomas varies with anatomical site (Omholt et al, 2011). So far, all of the published studies have analysed a small number of SNMM samples and the reported frequencies of mutations in SNMM vary considerably between these studies; KIT, 0-40\%; NRAS, 22-60\% and BRAF 0-6\% (Cohen et al, 2004; Beadling et al, 2008; Carvajal et al, 2011; Schoenewolf et al, 2012; Turri-Zanoni et al, 2012).

Although most of the primary SNMMs are localised at diagnosis, radical surgical resection is difficult (Bradley, 2006) and therefore effective, alternative treatment options are essential for patients with these tumours. Molecular targeted therapy is now available for patients with malignant melanomas. A phase III trial has shown that vemurafenib, a selective BRAF inhibitor, improves both progression-free and overall survival compared with standard systemic chemotherapy (Chapman et al, 2011). Phase II trials and case reports have shown promising effects of targeted therapy with imatinib and dasatinib for patients with KIT mutant melanomas (Woodman and Davies, 2010; Carvajal et al, 2011). Very recently, a phase II trial showed that patients with NRAS mutant melanomas might benefit from treatment with MEK1/2 inhibitor (Ascierto et al, 2013). These novel therapeutic advances stress the importance of investigating the mutations in these oncogenes in patients with SNMM.

Given the rarity of SNMM, the frequency of KIT, NRAS and $B R A F$ mutations has not been well characterised in these tumours. The purpose of the current study was to evaluate a large number of primary SNMMs in order to better define the frequency of KIT, NRAS and BRAF mutations.

\section{MATERIALS AND METHODS}

Tumour samples. Archival materials of formalin-fixed paraffinembedded blocks of 61 SNMMs were collected from pathology departments throughout Sweden. Patients were diagnosed between 1986 and 2011 and were reported to the Swedish National Cancer Registry. All clinical records and pathological reports were collected and reviewed. We retrieved information on diagnosis, classification, disease site, overall survival and clinical features such as clinically reported pigmentation of tumours and reports of ulceration in pathological assessment. When data could not be appropriately determined, they were coded as missing. Five samples were excluded because the sections contained too few tumour cells. Thus, overall 56 primary SNMMs were included and 12 of these cases were part of a previously published data set (Omholt et al, 2011). This study was approved by the Research Ethics Committee, Karolinska Institutet, Stockholm, Sweden.

Laser capture microdissection and DNA extraction. Sections of $5 \mu \mathrm{m}$ thickness were cut from formalin-fixed paraffin-embedded blocks and placed on plain slides. Sections were deparaffinised with two washes of xylene, rehydrated in increasing concentrations of ethanol, rinsed with deionised water, shortly stained with haematoxylin, rinsed with deionised water and dehydrated in decreased concentrations of ethanol and two washes of xylene.
Tumour cells were microdissected from sections by laser capture microdissection (LCM) using the Arcturus PixCell LCM System (Arcturus Engineering, Mountain View, CA, USA) according to the manufacturer's recommendations. Samples were incubated overnight with proteinase K-enriched digestion buffer (PicoPure DNA Extraction KIT, Arcturus Engineering) to extract the DNA from the dissected cells. Proteinase $\mathrm{K}$ was then inactivated by heating samples at $95^{\circ} \mathrm{C}$ for $10 \mathrm{~min}$.

Mutation analysis. Genomic DNA was subjected to first and nested PCR to amplify BRAF (exon 15), NRAS (exons 1 and 2) and KIT (exons 11, 13 and 17) genes. In the first PCR, the DNA was amplified in a $10 \mu \mathrm{l}$ mixture reaction containing $2.5 \mathrm{~mm}$ deoxynucleotide triphosphate, $5 \mathrm{U}_{\mu} \mathrm{l}^{-1}$ platinumTaq DNA polymerase (Invitrogen, Carlsbad, CA, USA), $50 \mathrm{pmol}^{-1} \mathrm{l}^{-1}$ of each primer, $10 \times$ PCR buffer, $50 \mathrm{~mm} \mathrm{MgCl}_{2}$ and $10 \mu \mathrm{g} \mu \mathrm{l}^{-1}$ bovine serum albumin. Two microlitres of the first PCR reaction was used as DNA template for the nested PCR. The DNA was extracted and purified from agarose gels by using QIAquick Gel Extraction Kit (Qiagen, Valencia, CA, USA). Sequencing reactions were performed in a final volume of $20 \mu \mathrm{l}$ using BigDye Terminator V1.1 Cycle Sequencing kit (Applied Biosystems, Foster City, CA, USA). The sequencing products were purified by ethanol precipitation, and automated DNA sequencing was performed by ABI PRISM3130xl Genetic Analyzer (Applied Biosystems). All mutations were confirmed by a second independent PCR and sequencing reaction. The primers used for amplification and sequencing are described in Supplementary Table 1.

Statistical analysis. Fisher's exact test was used to correlate the mutation status with clinicopathological features such as gender, ulceration, anatomical site and pigmentation. Age at diagnosis was compared between the mutated and wild-type group using Wilcoxon rank-sum test. Overall survival was estimated from the date of diagnosis to the date of death or last follow-up (1 November 2012). Patients who were alive at end of the study were censored. Survival data were available for all patients. Multivariate Cox regression model, Log-rank test and Kaplan-Meier graphs were used to assess the association of anatomical site with overall survival. All $P$-values were two-sided. $P$-values $<0.05$ were considered statistically significant.

\section{RESULTS}

Clinicopathological characteristics. Patient and tumour characteristics are listed in Table 1. Overall, there were 35 females and 21 males with a median age at diagnosis of 76 years. Thirty-four tumours were located in the nasal cavity and 22 in the paranasal sinuses (10 in the maxillary sinuses, 6 in the ethmoid sinuses and 6 tumours invaded the surrounding structures: 4 involved the orbit; one the skull base and another one spread to the retromaxillary infratemporal fossa).

Mutation analysis. Of the 56 primary SNMMs analysed, 12 (21\%) harboured KIT, NRAS or BRAF mutations and 44 (79\%) were wild type. Mutations in KIT, NRAS and BRAF occurred in a mutually exclusive manner. The difference between KIT, NRAS and BRAF mutation frequencies in SNMMs was borderline significant $(P=0.058)$.

KIT mutations were detected in 2 of the 56 SNMMs (4\%). Both tumours with KIT mutations contained the hotspot mutation L576P in exon 11 (Table 2). No mutations were observed in exons 13 and 17. In our previous study, we identified a much higher frequency of KIT mutations in vulvar melanomas, with mutations in 8 of 23 tumours (35\%; Omholt et al, 2011). Thus, in our material the difference between the updated results on KIT mutation 
frequency in SNMMs and that previously presented for vulvar melanomas is statistically significant $(P=0.001)$.

\begin{tabular}{|c|c|}
\hline Characteristics & Total $n=56$ \\
\hline \multicolumn{2}{|l|}{ Age at diagnosis, year } \\
\hline $\begin{array}{l}\text { Median } \\
\text { Mean } \\
\text { Range }\end{array}$ & $\begin{array}{c}76 \\
74 \\
52-97\end{array}$ \\
\hline \multicolumn{2}{|l|}{ Gender, $n$ (\%) } \\
\hline $\begin{array}{l}\text { Male } \\
\text { Female }\end{array}$ & $\begin{array}{l}21(37.5) \\
35(62.5)\end{array}$ \\
\hline \multicolumn{2}{|l|}{ Anatomical site, $\boldsymbol{n}(\%)$} \\
\hline $\begin{array}{l}\text { Nasal cavity } \\
\text { Paranasal sinus }\end{array}$ & $\begin{array}{l}34(60.7) \\
22(39.3)\end{array}$ \\
\hline \multicolumn{2}{|l|}{ Ulceration, n (\%) } \\
\hline $\begin{array}{l}\text { Present } \\
\text { Absent } \\
\text { Data missing }\end{array}$ & $\begin{array}{r}34(60.7) \\
14(25.0) \\
8(14.3)\end{array}$ \\
\hline \multicolumn{2}{|l|}{ Pigmentation, n (\%) } \\
\hline $\begin{array}{l}\text { Present } \\
\text { Absent } \\
\text { Data missing }\end{array}$ & $\begin{array}{r}23(41.1) \\
25(44.6) \\
8(14.3)\end{array}$ \\
\hline \multicolumn{2}{|l|}{ Ballantyne staging } \\
\hline $\begin{array}{l}\text { I } \\
\text { II } \\
\text { III } \\
\text { Data missing }\end{array}$ & $\begin{aligned} 52 & (92.8) \\
1 & (1.8) \\
1 & (1.8) \\
2 & (3.6)\end{aligned}$ \\
\hline Median survival, month (range) ${ }^{a}$ & $32(2-230)$ \\
\hline $\begin{array}{l}\text { Alive, } n \\
\text { Dead, } n\end{array}$ & $\begin{array}{l}10 \\
46\end{array}$ \\
\hline
\end{tabular}

NRAS mutations were identified in $8(14 \%)$ and $B R A F$ mutations in $2(4 \%)$ of the 56 SNMMs. Among the identified NRAS mutations, four were found in exon 1 (G12C, G12D, G12A and G13D) and four in exon 2 (Q61K, Q61R and Q61H $(n=2)$ ). The BRAF mutations consisted of one V600E and one V600K change. Both $B R A F$ mutated tumours were located in maxillary sinuses (Table 2).

Association of mutations with clinicopathological features. As the number of mutations identified was small, we compared the clinicopathological features between tumours with KIT, NRAS or $B R A F$ mutations and those lacking these mutations. Tumours with mutations were more likely to be located in the paranasal sinuses, whereas the wild-type lesions were more often found in the nasal cavity and the difference was statistically significant $(P=0.045$, Table 3). There was no difference between the mutated and wildtype group with respect to age at diagnosis, gender, ulceration and tumour pigmentation.

Survival. In univariate analysis, the age, anatomical site and clinical stage were significantly associated with overall survival. Patients with melanoma in the nasal cavity had a significantly better prognosis than those with a tumour in the paranasal sinuses (median survival, 39 vs 16 months; Log-rank $P=0.027$; Figure 1). This effect remained significant in a multivariate analysis after adjusting for age at diagnosis, gender, ulceration, pigmentation and clinical stage $(P=0.001)$. The mutation status of the tumours showed no association with the overall survival.

\section{DISCUSSION}

Mutational data on SNMM are rare and there are only a few published reports with limited number of tumours (listed in Table 4). In this study, which is the largest of its kind, to our knowledge, we screened primary SNMM for mutations in some of the most commonly mutated oncogenes in cutaneous melanoma. We identified KIT, NRAS and BRAF mutations in $4 \%, 14 \%$ and $4 \%$ of tumours, respectively. The finding of KIT mutations in only 2 of 56 SNMMs suggests that KIT mutations differ between mucosal melanomas at different sites, and that they are very rare in this subtype of mucosal melanomas. Altogether, the present results and those of our previous study on mucosal melanomas from several different sites show that the KIT mutation frequency in SNMM is

\begin{tabular}{|c|c|c|c|c|c|c|c|}
\hline Case & Gender & Age & Anatomical site & Gene & Exon & Nucleotide change & Amino-acid change \\
\hline 1 & $\mathrm{~F}$ & 63 & Nasal cavity & KIT & 11 & c. $1727 \mathrm{~T}>\mathrm{C}$ & p.L576P \\
\hline 2 & M & 65 & Maxillary sinus & KIT & 11 & c. $1727 \mathrm{~T}>\mathrm{C}$ & p.L576P \\
\hline 3 & $M$ & 88 & Maxillary sinus & NRAS & 1 & c. $34 \mathrm{G}>\mathrm{T}$ & p.G12C \\
\hline 4 & $\mathrm{~F}$ & 66 & Maxillary sinus & NRAS & 1 & c. $35 \mathrm{G}>\mathrm{A}$ & p.G12D \\
\hline 5 & $M$ & 78 & Ethmoid sinus & NRAS & 1 & c. $35 \mathrm{G}>\mathrm{C}$ & p.G12A \\
\hline 6 & $\mathrm{~F}$ & 97 & Nasal cavity & NRAS & 1 & c. $38 \mathrm{G}>\mathrm{A}$ & p.G13D \\
\hline 7 & $M$ & 70 & Nasal cavity & NRAS & 2 & c. $181 C>A$ & p.Q61K \\
\hline 8 & $\mathrm{~F}$ & 58 & Maxillary sinus & NRAS & 2 & c. $182 A>G$ & p.Q61R \\
\hline 9 & $M$ & 68 & Maxillary sinus & NRAS & 2 & c. $183 A>C$ & p.Q61H \\
\hline 10 & $\mathrm{~F}$ & 82 & Nasal cavity & NRAS & 2 & c. $183 \mathrm{~A}>\mathrm{C}$ & p.Q61H \\
\hline 11 & $\mathrm{~F}$ & 80 & Maxillary sinus & BRAF & 15 & c. $1799 \mathrm{~T}>\mathrm{A}$ & p.V600E \\
\hline 12 & $\mathrm{~F}$ & 52 & Maxillary sinus & $B R A F$ & 15 & c. $1798 \mathrm{GT}>\mathrm{AA}$ & p.V600K \\
\hline
\end{tabular}


Table 3. Association of mutation status with clinical features in primary SNMMs $(n=56)$

\begin{tabular}{|l|c|c|c|}
\hline & $\begin{array}{c}\text { Mutated } \\
\mathbf{n}=\mathbf{1 2}\end{array}$ & $\begin{array}{c}\text { Wild type }^{\mathbf{b}} \\
\mathbf{n = 4 4}\end{array}$ & P-value \\
\hline Median age, year (range) & $69(52-97)$ & $76(52-93)$ & 0.347 \\
\hline Gender, $\boldsymbol{n}$ (\%) & & & 0.748 \\
\hline Male & $5(41.7)$ & $16(36.4)$ & \\
Female & $7(58.3)$ & $28(63.6)$ & \\
\hline Anatomical site, $\boldsymbol{n}$ (\%) & & & \\
\hline Nasal cavity & $4(33.3)$ & $30(68.2)$ & 0.045 \\
Paranasal sinus & $8(66.7)$ & $14(31.8)$ & \\
\hline Ulceration, $\boldsymbol{n}$ (\%) & & & 0.656 \\
\hline Present & $6(50.0)$ & $28(63.6)$ & \\
Absent & $1(8.3)$ & $13(29.6)$ & \\
Data missing & $5(41.7)$ & $3(6.8)$ & \\
\hline Pigmentation, $\boldsymbol{n}$ (\%) & & & 0.189 \\
\hline Present & $3(25.0)$ & $20(45.4)$ & \\
Absent & $8(66.7)$ & $19(43.2)$ & \\
Data missing & $1(8.3)$ & $5(11.4)$ & \\
\hline
\end{tabular}

Abbreviation: SNMM = sinonasal mucosal melanoma.

a Mutated in KIT, NRAS or BRAF.

b Wild type in KIT, NRAS and BRAF.

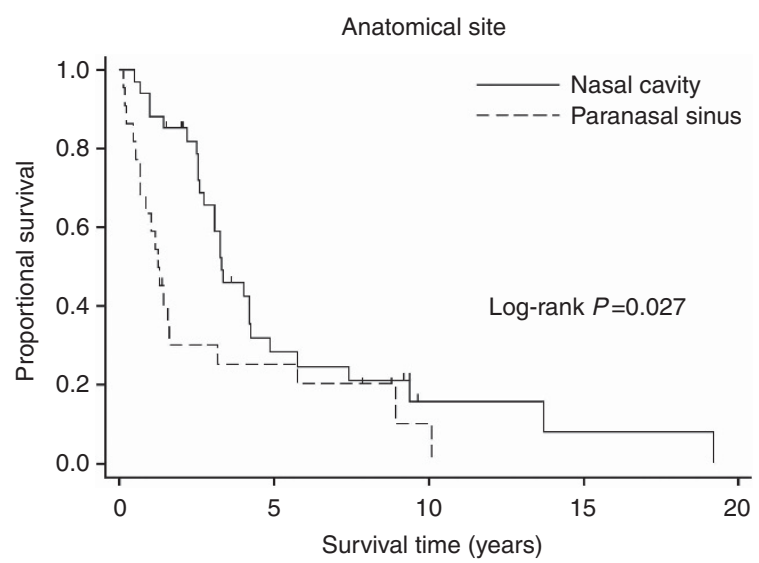

Number at risk

Nasal cavity $\quad 34$

Paranasal sinus 22

8

5

2

1

0

0

Figure 1. Overall survival of patients with SNMM located in the nasal cavity and paranasal sinuses. significantly lower than that in vulvar melanomas (Omholt et al, 2011). Our results are also supported by Schoenewolf et al (2012), who in a recent study on sinonasal and vulvovaginal melanomas found no KIT mutations in 12 sinonasal tumours compared with 5 mutations in 11 vulvovaginal tumours (45\%). Beadling et al (2008) also found a lower frequency of KIT mutations in melanomas of the head and neck ( 3 of $36 ; 8 \%$ ) compared with melanomas of the anorectum/vulva/vagina (4 of 9; 44\%).

In contrast to KIT mutations, the frequency of BRAF mutations is generally low in mucosal melanomas and does not seem to vary significantly between different sites (Omholt et al, 2011). In the current study, BRAF mutations were identified in $4 \%$ of SNMMs, which is similar to that detected in mucosal melanomas from other sites such as the vulva, vagina and anorectum (Curtin et al, 2006; Omholt et al, 2011).

The frequency of NRAS mutations that we identified in SNMM (14\%) seem to be similar to that seen in cutaneous melanomas (Omholt et al, 2003; Edlundh-Rose et al, 2006; Lee et al, 2011). Interestingly, however, the types of NRAS mutations that we detected in SNMM differ from the types that predominate in cutaneous melanomas. In cutaneous melanomas, substitutions of glutamine for either arginine or lysine at codon 61 (Q61R and Q61K) represent the two most common NRAS mutations (Hocker and Tsao, 2007). In the current study, only two of eight NRASmutated tumours contained either of these mutations, whereas two had other alterations at codon 61 and four tumours contained mutations at codon 12 or 13 in exon 1 . This indicates that NRAS mutations in mucosal melanomas, as opposed to cutaneous melanomas, are present in exon 1 and 2 with similar frequencies (Omholt et al, 2011; Turri-Zanoni et al, 2012). The NRAS mutations at codon 12 and 13 also predominate in other malignancies such as haematological cancers (Ward et al, 2012). The different pattern of NRAS mutations in mucosal melanoma, compared with cutaneous melanoma, possibly indicate an aetiology hitherto unknown but different from UV-radiation.

Interestingly, we found that mucosal melanomas located in the sinuses have a higher frequency of KIT, NRAS or BRAF mutations than those located in the nasal cavity. We also found that patients with disease emerging from the sinuses have a worse prognosis compared with those with tumours originating from the nasal cavity. This has also been observed in other studies (Liétin et al, 2010; Jethanamest et al, 2011). In the current study, the poor prognosis might be the result of more advanced tumour stage because in six cases the paranasal tumours invaded the surrounding structures. It remains to be addressed whether the adverse prognosis is associated with more aggressive biology and whether this is linked to the presence of oncogene mutations. Here we found no difference in overall survival between patients with mutated melanomas and those with wild-type melanomas;

Table 4. Summary of KIT, NRAS and BRAF mutations in SNMM

\begin{tabular}{|c|c|c|c|c|}
\hline Reference & SNMM & KIT & NRAS & BRAF \\
\hline Cohen et al (2004) & 17 & - & - & $5.9 \%(1 / 17)$ \\
\hline Beadling et al (2008) & 29 & $8.4 \%(3 / 36)^{a}$ & $\mathrm{~b}$ & $0.0 \%(0 / 29)$ \\
\hline Carvajal et al (2011) & 5 & $40.0 \%(2 / 5)$ & $60.0 \%(3 / 5)$ & $0.0 \%(0 / 5)$ \\
\hline Schoenewolf et al (2012) & 12 & $0.0 \%(0 / 12)$ & - & - \\
\hline Turri-Zanoni et al (2012) & 32 & $12.5 \%(4 / 32)$ & $21.9 \%(7 / 32)$ & $3.1 \%(1 / 32)$ \\
\hline Current study & 56 & $3.6 \%(2 / 56)$ & $14.3 \%(8 / 56)$ & $3.6 \%(2 / 56)$ \\
\hline Total & 151 & $7.8 \%(11 / 141)$ & $19.3 \%(18 / 93)$ & $2.9 \%(4 / 139)$ \\
\hline
\end{tabular}


however, the number of mutations identified are too small, which can skew the results. In our previous study, we found that KIT mutations as well as NRAS mutations associated with poor survival in univariate but not in multivariate analysis (Omholt et al, 2011). In contrast to our results, a recent Chinese study showed that KIT mutations adversely affected survival (Kong et al, 2011); however, in this report mucosal melanomas were combined with cutaneous melanomas and a multivariate analysis was not performed.

The frequencies of KIT and BRAF mutations in SNMMs suggest that only a minority of patients with SNMM may benefit from treatment with KIT and BRAF inhibitors. The higher proportion of NRAS-mutated tumours suggest that it may be worthwhile to perform studies using MEK inhibitors, which have shown promising phase II results in cutaneous melanoma with NRAS mutations (Ascierto et al, 2013). It would be intriguing to investigate whether tumours with codon 12-13 activating mutations have similar therapeutic outcome as cutaneous melanomas with codon 61 mutations. Mutation analysis might yield positive results particularly in tumours from paranasal sinuses, as our results indicate that tumours from these areas more probably harbour mutations in KIT, NRAS or BRAF than the tumours from the nasal cavity. Still, a majority of SNMM has other unknown underlying oncogenic driver mutations that need to be addressed in future studies. Very recently, a high frequency of somatic mutations have been discovered in the promoter of telomerase reverse transcriptase (TERT) in cutaneous melanoma, resulting in increased transcriptional activity at the TERT promoter that might act as driver mutations (Horn et al, 2013; Huang et al, 2013). Presence of mutations in TERT promoter is still waiting to be determined in mucosal melanomas.

In conclusion, our results show that KIT, NRAS and BRAF mutations occur at low frequencies in SNMM, and confirm our recent findings that the frequency of KIT in mucosal melanoma mutations vary significantly between different anatomical sites.

\section{ACKNOWLEDGEMENTS}

We express our gratitude to Bo Nilsson for advice and help with statistical analyses. Drs Lena Kanter and Lars Olding for help with the re-evaluating tumour histopathology. We also thank Diana Lindén, Lisa Viberg and Susanne Thorell for collecting tumour samples. This study was financed by grants from the Swedish Cancer Society, the Radiumhemmet Research Funds, the Karolinska Institutet Research Funds and the ACTA Otolaryngologica Foundation. The Ministry of Higher Education and Scientific Research in Iraqi-Kurdistan Regional Government is acknowledged for financial support (AZ).

\section{CONFLICT OF INTEREST}

The authors declare no conflict of interest.

\section{REFERENCES}

Ascierto PA, Schadendorf D, Berking C, Agarwala SS, van Herpen CM, Queirolo P, Blank CU, Hauschild A, Beck JT, St-Pierre A, Niazi F, Wandel S, Peters M, Zubel A, Dummer R (2013) MEK162 for patients with advanced melanoma harbouring NRAS or Val600 BRAF mutations: a non-randomised, open-label phase 2 study. Lancet Oncol 14: 249-256.

Beadling C, Jacobson-Dunlop E, Hodi FS, Le C, Warrick A, Patterson J, Town A, Harlow A, Cruz F, Azar S, Rubin BP, Muller S, West R, Heinrich MC, Corless CL (2008) KIT gene mutations and copy number in melanoma subtypes. Clin Cancer Res 14: 6821-6828.
Bradley PJ (2006) Primary malignant mucosal melanoma of the head and neck. Curr Opin Otolaryngol Head Neck Surg 14: 100-104.

Carvajal RD, Antonescu CR, Wolchok JD, Chapman PB, Roman RA, Teitcher J, Panageas KS, Busam KJ, Chmielowski B, Lutzky J, Pavlick AC, Fusco A, Cane L, Takebe N, Vemula S, Bouvier N, Bastian BC, Schwartz GK (2011) KIT as a therapeutic target in metastatic melanoma. JAMA 305: 2327-2334.

Chapman PB, Hauschild A, Robert C, Haanen JB, Ascierto P, Larkin J, Dummer R, Garbe C, Testori A, Maio M, Hogg D, Lorigan P, Lebbe C, Jouary T, Schadendorf D, Ribas A, O’Day SJ, Sosman JA, Kirkwood JM, Eggermont AM, Dreno B, Nolop K, Li J, Nelson B, Hou J, Lee RJ, Flaherty KT, McArthur GA, Group B-S (2011) Improved survival with vemurafenib in melanoma with BRAF V600E mutation. N Engl J Med 364: 2507-2516.

Clifton N, Harrison L, Bradley PJ, Jones NS (2011) Malignant melanoma of nasal cavity and paranasal sinuses: report of 24 patients and literature review. J Laryngol Otol 125: 479-485.

Cohen Y, Rosenbaum E, Begum S, Goldenberg D, Esche C, Lavie O, Sidransky D, Westra WH (2004) Exon 15 BRAF mutations are uncommon in melanomas arising in nonsun-exposed sites. Clin Cancer Res 10: 3444-3447.

Curtin JA, Busam K, Pinkel D, Bastian BC (2006) Somatic activation of KIT in distinct subtypes of melanoma. J Clin Oncol 24: 4340-4346.

Curtin JA, Fridlyand J, Kageshita T, Patel HN, Busam KJ, Kutzner H, Cho KH, Aiba S, Bröcker EB, LeBoit PE, Pinkel D, Bastian BC (2005) Distinct sets of genetic alterations in melanoma. $N$ Engl J Med 353: 2135-2147.

Davies H, Bignell GR, Cox C, Stephens P, Edkins S, Clegg S, Teague J, Woffendin H, Garnett MJ, Bottomley W, Davis N, Dicks E, Ewing R, Floyd Y, Gray K, Hall S, Hawes R, Hughes J, Kosmidou V, Menzies A, Mould C, Parker A, Stevens C, Watt S, Hooper S, Wilson R, Jayatilake H, Gusterson BA, Cooper C, Shipley J, Hargrave D, Pritchard-Jones K, Maitland N, Chenevix-Trench G, Riggins GJ, Bigner DD, Palmieri G, Cossu A, Flanagan A, Nicholson A, Ho JW, Leung SY, Yuen ST, Weber BL, Seigler HF, Darrow TL, Paterson H, Marais R, Marshall CJ, Wooster R, Stratton MR, Futreal PA (2002) Mutations of the BRAF gene in human cancer. Nature 417: 949-954.

Edlundh-Rose E, Egyházi S, Omholt K, Månsson-Brahme E, Platz A, Hansson J, Lundeberg J (2006) NRAS and BRAF mutations in melanoma tumours in relation to clinical characteristics: a study based on mutation screening by pyrosequencing. Melanoma Res 16: 471-478.

Ellerhorst JA, Greene VR, Ekmekcioglu S, Warneke CL, Johnson MM, Cooke CP, Wang LE, Prieto VG, Gershenwald JE, Wei Q, Grimm EA (2011) Clinical correlates of NRAS and BRAF mutations in primary human melanoma. Clin Cancer Res 17: 229-235.

Handolias D, Salemi R, Murray W, Tan A, Liu W, Viros A, Dobrovic A, Kelly J, McArthur GA (2010) Mutations in KIT occur at low frequency in melanomas arising from anatomical sites associated with chronic and intermittent sun exposure. Pigment Cell Melanoma Res 23: 210-215.

Harbo G, Grau C, Bundgaard T, Overgaard M, Elbrond O, Sogaard H, Overgaard J (1997) Cancer of the nasal cavity and paranasal sinuses. A clinico-pathological study of 277 patients. Acta Oncol 36: 45-50.

Hocker T, Tsao H (2007) Ultraviolet radiation and melanoma: a systematic review and analysis of reported sequence variants. Hum Mutat 28: 578-588.

Horn S, Figl A, Rachakonda PS, Fischer C, Sucker A, Gast A, Kadel S, Moll I, Nagore E, Hemminki K, Schadendorf D, Kumar R (2013) TERT promoter mutations in familial and sporadic melanoma. Science 339: 959-961.

Huang FW, Hodis E, Xu MJ, Kryukov GV, Chin L, Garraway LA (2013) Highly recurrent TERT promoter mutations in human melanoma. Science 339: 957-959.

Jangard M, Hansson J, Ragnarsson-Olding B (2013) Primary sinonasal malignant melanoma: a nationwide study of the Swedish population, 1960-2000. Rhinology 51: 22-30.

Jethanamest D, Vila PM, Sikora AG, Morris LGT (2011) Predictors of survival in mucosal melanoma of the head and neck. Ann Surg Oncol 18: $2748-2756$

Jovanovic B, Kröckel D, Linden D, Nilsson B, Egyhazi S, Hansson J (2008) Lack of cytoplasmic ERK activation is an independent adverse prognostic factor in primary cutaneous melanoma. J Invest Dermatol 128: 2696-2704.

Kong Y, Si L, Zhu Y, Xu X, Corless CL, Flaherty KT, Li L, Li H, Sheng X, Cui C, Chi Z, Li S, Han M, Mao L, Lu A, Guo J (2011) Large-scale analysis of KIT aberrations in Chinese patients with melanoma. Clin Cancer Res 17: 1684-1691. 
Lee JH, Choi JW, Kim YS (2011) Frequencies of BRAF and NRAS mutations are different in histological types and sites of origin of cutaneous melanoma: a meta-analysis. Br J Dermatol 164: 776-784.

Liétin B, Montalban A, Louvrier C, Kemeny JL, Mom T, Gilain L (2010) Sinonasal mucosal melanomas. Eur Ann Otorhinolaryngol Head Neck Dis 127: $70-76$.

Lund VJ, Chisholm EJ, Howard DJ, Wei WI (2012) Sinonasal malignant melanoma: an analysis of 115 cases assessing outcomes of surgery, postoperative radiotherapy and endoscopic resection. Rhinology 50: 203-210.

Norlander T, Frodin JE, Silfversward C, Anggard A (2003) Decreasing incidence of malignant tumors of the paranasal sinuses in Sweden. An analysis of 141 consecutive cases at Karolinska Hospital from 1960 to 1980. Ann Otol Rhinol Laryngol 112: 236-241.

Omholt K, Grafström E, Kanter-Lewensohn L, Hansson J, Ragnarsson-Olding BK (2011) KIT pathway alterations in mucosal melanomas of the vulva and other sites. Clin Cancer Res 17: 3933-3942.

Omholt K, Platz A, Kanter L, Ringborg U, Hansson J (2003) NRAS and BRAF mutations arise early during melanoma pathogenesis and are preserved throughout tumor progression. Clin Cancer Res 9: 6483-6488.

Schoenewolf NL, Bull C, Belloni B, Holzmann D, Tonolla S, Lang R, Mihic-Probst D, Andres C, Dummer R (2012) Sinonasal, genital and acrolentiginous melanomas show distinct characteristics of KIT expression and mutations. Eur J Cancer 48: 1842-1852.

The National Board of Health and Welfare (1960-2009) The Swedish Cancer Registry: Cancer in Sweden. National Board of Health and Welfare: Stockholm.

Turri-Zanoni M, Medicina D, Lombardi D, Ungari M, Balzarini P, Rossini C, Pellegrini W, Battaglia P, Capella C, Castelnuovo P, Palmedo G, Facchetti F, Kutzner H, Nicolai P, Vermi W (2012) Sinonasal mucosal melanoma: molecular profile and therapeutic implications from a series of 32 cases. Head Neck; epub ahead of print 12 July 2012; doi:10.1002/hed.23079.

Ward AF, Braun BS, Shannon KM (2012) Targeting oncogenic Ras signaling in hematologic malignancies. Blood 120: 3397-3406.

Woodman SE, Davies MA (2010) Targeting KIT in melanoma: a paradigm of molecular medicine and targeted therapeutics. Biochem Pharmacol 80: 568-574.

This work is published under the standard license to publish agreement. After 12 months the work will become freely available and the license terms will switch to a Creative Commons AttributionNonCommercial-Share Alike 3.0 Unported License.

Supplementary Information accompanies this paper on British Journal of Cancer website (http://www.nature.com/bjc) 